\title{
Studies on the amount and composition of digesta flowing through the duodenum of dairy cows. 1. Rate of flow of digesta measured direct and estimated indirect by the indicator dilution technique
}

\author{
A. Th. van 't Klooster'1, A. Kemp², J. H. Geurink² and P. A. M. Rogers 3 \\ 1 Department of Animal Physiology, Agricultural University, Wageningen, the Nether- \\ lands \\ 2 Institute for Biological and Chemical Research on Field Crops and Herbage (IBS), \\ Wageningen, the Netherlands \\ 3 Agricultural Institute, Dunsinea, Castleknock, Dublin, Ireland
}

Received: 13 October 1972

\section{Summary}

1. Two Friesian cows were fitted with re-entrant cannulas in the duodenum. Balance trials were carried out on each of three diets. The flow of digesta through the duodenum was measured directly for $120 \mathrm{~h}$ during each balance trial.

2. On a ration of hay and concentrate the mean flows and their standard deviations $(\mathrm{kg} / \mathrm{h})$ were $8.4 \pm 1.32$ and $12.0 \pm 1.94$ for the two cows. On a ration of fresh-mown grass the flows were $9.4 \pm 1.23$ and $14.9 \pm 2.59 \mathrm{~kg} / \mathrm{h}$. Day-to-day variation and differences in the flow of digesta between daylight and night hours were small (Table 3 ).

3. Poly (ethylene glycol) (PEG) and chromium sesquioxide $\left(\mathrm{Cr}_{2} \mathrm{O}_{3}\right)$ were administered into the rumen twice daily before and during each balance period. The percentages of the dose which were recovered in the duodenal digesta were $100.3 \pm 1.5$ and $98.3 \pm$ 6.0 for PEG and $\mathrm{Cr}_{2} \mathrm{O}_{3}$, respectively; the recoveries from faeces were $99.7 \pm 3.9$ and $99.0 \pm 5.0 \%$, respectively.

4. Proportional and spot samples of digesta were analysed for their content of PEG, $\mathrm{Cr}_{2} \mathrm{O}_{3}$, dry matter, calcium and magnesium. The mean composition of spot samples taken at 2-hour intervals agreed very well with that of the proportional samples collected during the same hours. It was concluded that an indirect estimate of flow rate of digesta from the PEG and $\mathrm{Cr}_{2} \mathrm{O}_{3}$ content of spot samples taken at 2-hour intervals over $120 \mathrm{~h}$ provide a convenient alternative to the more tedious procedure of directly measuring and sampling the flow of digesta through re-entrant cannulas.

\section{Introduction}

The amount of digesta flowing through the duodenum has been measured direct in sheep (Phillipson, 1952; Phillipson and Ash, 1965; van 't Klooster et al., 1969; MacRae and Ulyatt, 1972) and in cattle (Sineshchekov, 1965; Dirksen et al., 1972). Such direct measurements involve the use of re-entrant duodenal cannulas. The complete removal and return of the digesta can, in itself, influence the flow rate (Phillipson, 1952; Hogan 
and Phillipson, 1960). The management and labour involved in working with re-entrantfistulated animals is greater and the life expectancy of the animals is shorter than when animals fitted with simple $\mathrm{T}$-piece cannulas are used.

Chromium sesquioxide $\left(\mathrm{Cr}_{2} \mathrm{O}_{3}\right)$ (Corbett et al., 1960) and poly (ethylene glycol) (PEG) (Sperber et al., 1953) are now extensively used to estimate indirectly the flow of digesta in many parts of the alimentary tract. Harris and Phillipson (1962) found $\mathrm{Cr}_{2} \mathrm{O}_{3}$ recoveries of $88-93 \%$ from the duodenal digesta of re-entrant-fistulated sheep during six $12-\mathrm{h}$ collections. They proposed the use of estimated flow rates of digesta calculated by correcting the measured flow to give $100 \%$ recovery of the indicator. Since then to reduce the labour involved in total collections of duodenal digesta over long periods, other workers have combined the indirect method with direct measurements over relatively short periods (12-24 h) (Bruce et al., 1966; Topps et al., 1968; MacRae and Armstrong, 1969; MacRae and Ulyatt, 1972).

Van 't Klooster et al. (1969) found recoveries of almost $100 \%$ for PEG and $\mathrm{Cr}_{2} \mathrm{O}_{3}$ from duodenal digesta of sheep. Total collections were made over periods of $120 \mathrm{~h}$. Recoveries were low on the 1 st day of collection, but were almost complete by the end of the 5th day. During these experiments a spot sampling technique was given a preliminary trial. The results showed that an accurate indirect estimate of the flow of digesta could be made from the PEG and $\mathrm{Cr}_{2} \mathrm{O}_{3}$ content of spot samples taken more frequently than every $4 \mathrm{~h}$ over $120 \mathrm{~h}$. The indicator dilution method was used in subsequent experiments with cows fitted with T-piece cannulas in the duodenum and ileum (van 't Klooster and Rogers, 1969). Digesta samples were taken every $2 \mathrm{~h}$ over 5 days. The accuracy of the sampling method and the validity of the results could not be tested or proved, as no direct measurements were made.

The present experiments were designed to compare within the same experiments direct measurements of the flow of digesta and nutrients through the duodenum of cows with indirect estimates based on the content of $\mathrm{PEG}$ and $\mathrm{Cr}_{2} \mathrm{O}_{3}$ in the duodenal digesta.

\section{Experimental}

\section{Animals}

Two Friesian cows ( 3 and 4) were fitted with re-entrant cannulas in the duodenum. The surgical technique was similar to that used by Hogan and Phillipson (1960) in sheep. Surgery was done under local anaesthesia with the cows standing. Curved cannulas of hard plastic, inner diameter $22 \mathrm{~mm}$, were used. The cannulas were fitted at least 4 weeks before the start of the trials. Both cows had also been fitted with rumen cannulas as well.

\section{Rations and experimental periods}

Table 1 shows the details of the rations. Cow 3 was given extra $\mathrm{Mg}$ as calcined magnesite (25 g/day) at $07 \mathrm{~h} 00$ and $19 \mathrm{~h} 00$ to study the site of $\mathrm{Mg}$ absorption at two levels of $\mathrm{Mg}$ intake (Kemp et al., 1973).

Food was offered at $06 \mathrm{~h} 00$ and $18 \mathrm{~h} 00$ in Exp. 1 and was consumed in about $1.5 \mathrm{~h}$. In Exp. 2, the grass was offered at $06 \mathrm{~h} 00$ and $16 \mathrm{~h} 00$ and was consumed in $4-5 \mathrm{~h}$. In Exp. 3, the grass was offered more frequently over the $24 \mathrm{~h}$. Grass was mown each day.

The preliminary feeding periods lasted for 14, 5 and 4 days in Exp. 1, 2 and 3, respectively. The balance period lasted for 8 days in Exp. 1, and 10 days in Exp. 2 and 3 (Kemp et al., 1960). During this time the intake of feed and the output of faeces, urine and milk were measured and sampled. Feed refusals were weighed and sampled. 
Table 1. Details of the experimental rations consumed by the cows.

\begin{tabular}{|c|c|c|c|c|c|}
\hline $\begin{array}{l}\text { Exp. } \\
\text { No }\end{array}$ & $\begin{array}{l}\text { Cow } \\
\text { no }\end{array}$ & $\begin{array}{l}\text { Milk } \\
\text { yield } \\
1 / \text { day }\end{array}$ & Rations & $\begin{array}{l}\text { DM } \\
\text { intake } \\
\text { (kg/day) }\end{array}$ & $\begin{array}{l}\text { Added } \\
\mathrm{MgO} \\
\text { (g/day) }\end{array}$ \\
\hline 1 & $\begin{array}{l}3 \\
4\end{array}$ & $\begin{array}{l}15.46 \\
16.00\end{array}$ & $\begin{array}{l}\text { hay and } \\
\text { concentrates } 1\end{array}$ & $\begin{array}{l}13.19 \\
12.27\end{array}$ & $\begin{array}{r}50 \\
0\end{array}$ \\
\hline 2 & 3 & $\begin{array}{l}10.40 \\
11.99\end{array}$ & $\begin{array}{l}\text { fresh-mown } \\
\text { herbage at early } \\
\text { stage of growth }\end{array}$ & $\begin{array}{l}9.61 \\
-\end{array}$ & $\begin{array}{r}50 \\
0\end{array}$ \\
\hline 3 & $\begin{array}{l}3 \\
4\end{array}$ & $\begin{array}{l}11.78 \\
11.61\end{array}$ & $\begin{array}{l}\text { fresh-mown } \\
\text { mature } \\
\text { herbage }\end{array}$ & $\begin{array}{r}11.48 \\
9.37\end{array}$ & $\begin{array}{r}50 \\
0\end{array}$ \\
\hline
\end{tabular}

1 Cow 3 and 4 were offered 8 and $7 \mathrm{~kg}$ of hay, respectively. Both cows receveid $8 \mathrm{~kg}$ concentrates.

Indicator dosage

During and in the 5 days preceding the collection periods, $100 \mathrm{~g}$ PEG and $5.25 \mathrm{~g}$ $\mathrm{Cr}_{2} \mathrm{O}_{3}$ were administered twice daily, at $07 \mathrm{~h} 00$ and $19 \mathrm{~h} 00$. PEG was dissolved in 1 litre of water and was mixed with 7 liters of rumen fluid which had been withdrawn just previously. The mixture was distributed as evenly as possible throughout the rumen in about 5 min (van 't Klooster and Rogers, 1969). Shredded paper, impregnated with $\mathrm{Cr}_{2} \mathrm{O}_{3}$, was compressed into a cigar shape in filter paper and was administered via the rumen cannula with the help of a simple gun.

Measurement of the flow of digesta and sampling procedure

The digesta were collected, directly measured and sampled from the re-entrant cannulas for 120 hours in the middle of each balance period. The proximal part of the re-entrant cannula was connected by a plastic tube to a 3-litre bottle placed in a water-bath $\left(40^{\circ} \mathrm{C}\right)$ behind the cow. Digesta from the proximal duodenum were then free to flow into the bottle. When 1-2 litres had collected, the tube was transferred to another empty bottle. The amount collected was weighed and recorded. Each collection was sampled proportionally ( $2 \%_{0}$ by weight). These samples, designated $\mathbf{P}$, were transferred to a separate plastic bottle for each hour of the 120 -hour period. At the end of each hour, the sample bottle was sealed and stored at $-25^{\circ} \mathrm{C}$ until required for analysis. The time of each collection was recorded. Notes were kept of whether or not the cows were eating, ruminating, standing or lying. Immediately after each sampling, the digesta remaining in the collection bottle were poured into a funnel and returned by gravity to the distal part of the cannula, through a plastic tube. The outflow and inflow tubes were attached to the balance harness. They operated whether the cows were standing or lying.

Spot samples, designated NP, were taken hourly at the half hour for $120 \mathrm{~h} ; 200 \mathrm{ml}$ were removed from whatever digesta had collected in the 3-litre bottle at the time, usually $0.6-0.4$ litre. These samples were stored separately at $-25^{\circ} \mathrm{C}$ until required for analysis.

\section{Digesta samples used for analysis}

The $\mathrm{P}$ and NP samples taken during the even hours were analysed for their content of $\mathrm{PEG}, \mathrm{Cr}_{2} \mathrm{O}_{3}$, dry matter (DM), $\mathrm{Ca}$ and $\mathrm{Mg}$. 
When it appeared from these analyses that the composition of the $P$ samples did not differ significantly from that of the NP samples, it was decided to combine the remaining (odd-hour) samples to save time and work. Fixed amounts of the $60 \mathrm{P}$ samples for the odd hours were bulked for each cow to form a day sample for each of the 5 days. Each of these day samples was analysed as before. The 60 NP samples for the odd hours were bulked to give one sample per cow.

\section{Analytical procedures}

PEG was determined by the method of Hydén (1955). The turbidity was read exactly $10 \mathrm{~min}$ after the addition of trichloroacetic acid. The standard deviation of single estimates was $\pm 0.7 \%$.

Cr was measured by atomic absorption flame spectrophotometry after ashing of the digesta and faeces (van 't Klooster et al., 1969). The standard deviation of single estimates was $3.2 \%$. Because of this high standard deviation, the accumulated samples were analysed at least four times and the mean of the results was used for the calculations.

DM was determined by drying in a hot-air oven at $103^{\circ} \mathrm{C}$ to constant weight. Ca and $\mathrm{Mg}$ were determined by atomic absorption flame spectrophotometry. Known amounts of the digesta samples were acidified. After centrifugation appropriate dilutions of the supernatent were made with a strontium chloride solution.

\section{Calculation of the recoveries of $P E G$ and $\mathrm{Cr}_{2} \mathrm{O}_{3}$}

The amount of indicator recovered from the duodenal digesta in the P samples was calculated separately for the even and odd hours. Recovery during the even hours was calculated by summation of the products of the observed flow rates $(\mathrm{kg} / \mathrm{h})$ for those hours and the indicator content of the corresponding $P$ samples. Recovery during the odd hours was calculated by multiplying the mean observed flow rate $(\mathrm{kg} / 12 \mathrm{~h})$ for the 12 odd hours of each day by the indicator content of the corresponding day samples, described above. The daily recovery was the sum of the amounts recovered during the even and odd hours of that day. The mean recoveries and their standard deviations were calculated for each 5-day period and expressed as a percentage of the daily dose.

The recovery of indicators from the faeces was calculated by multiplying the indicator content in a representative sample of the faeces with the daily amount of faeces produced.

\section{Results}

\section{Flow of digesta}

The observed flow of digesta was intermittent. Gushes varied between $100-500 \mathrm{ml}$ and were separated by intervals of less than 1 to more than $15 \mathrm{~min}$, during which time little or no digesta flowed out of the proximal part of the cannula.

Variation in the hourly total flows was not great, as can be seen in Fig. 1 and Table 2. The coefficient of variation (CV) of the hourly flow was $16 \%$ in Exp. 1 and $17 \%$ in Exp. 2 for both animals. In Exp. 3 the CV was lower, 12 and $13 \%$ for cows 3 and 4 , respectively.

The CV for day-to-day variation in both cows was about $10 \%$ in Exp. 1 and 2 . In Exp. 3 in which grass was fed in several portions spread over the day, this variation was only about 1 to $2 \%$. The relatively high CV in Exp. 1 was probably due to feeding the 


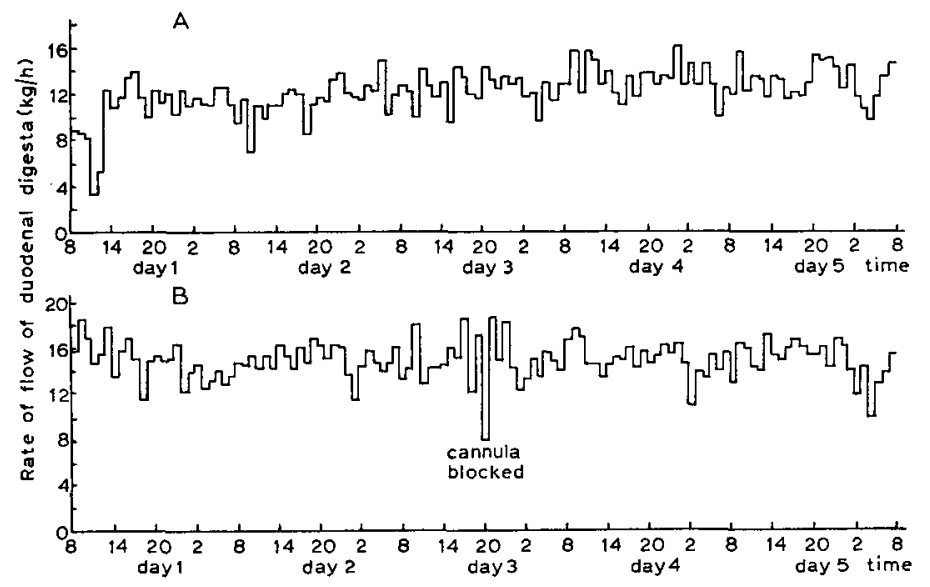

Fig. 1. Quantities per hour of duodenal contents flowing through the re-entrant cannula of cow 3 on a hay and concentrate ration (A) and on freshly mown grass (B). Mean flow rate $(\mathrm{kg} / \mathrm{h}): A$ $12.02 \pm 1.94 ; \mathrm{B} 14.72 \pm 1.73$.

cows twice a day and also to the decreased flow rate on day 1 and the small gradual increase in the flow rate thereafter, as can be seen for cow 3 in Fig. 1 . No such systematic variation occurred in Exp. 3.

In Exp. 2 a decreased flow occurred on day 5, especially in cow 4. The grass fed in this experiment was not readily eaten, and cow 4 refused to eat on day 5 . The grass was subsequently found to be low in sodium $(\mathrm{Na})$ and chlorine $(\mathrm{Cl})$, but no other abnormalities were found. The decreasing DM intake in Exp. 2 (which occurred also in cow 3).

Table 2. Mean flow rates $(\mathrm{kg} / \mathrm{h})$ of duodenal digesta of cows 3 and 4 . The ineans with standard deviations for all hours $(120 \mathrm{~h})$, for 24-hour periods and for the daylight and night hours are given for each experiment separately.

\begin{tabular}{lllll}
$\begin{array}{l}\text { Number of } \\
\text { samples }\end{array}$ & Cow 3 & Cow 4 & \\
\cline { 2 - 3 } & mean & SD & mean & SD
\end{tabular}

Exp. 1

all hours

24-hour periods

daylight hours

night hours

120
5
5
5

$\begin{array}{llll}12.0 & 1.94 & 8.4 & 1.32 \\ 12.0 & 1.03 & 8.4 & 0.76 \\ 11.6 & 1.43 & 8.5 & 0.80 \\ 12.4 & 0.66 & 8.3 & 0.84\end{array}$

Exp. 2

all hours

24-hour periods

daylight hours

14.9

night hours

14.9

14.7

15.1

2.59

1.56

1.99

1.00

8.8

8.8

1.19

5

Exp. 3

all hours

24-hour periods

daylight hours

120
5
5
5

14.7
14.7
15.2
14.2

1.73

1.73
0.14

0.24
0.30

8.7
8.8

1.49

1.19
1.19

1.22

night hours

14.2

$\begin{array}{ll}9.4 & 1.23 \\ 9.4 & 0.15 \\ 9.5 & 0.25 \\ 9.2 & 0.24\end{array}$


AMOUNT AND COMPOSITION OF DIGESTA IN THE COW'S DUODENUM 1.

Table 3. Analysis of variance on differences between 24-hour periods and between daylight and night hours.

\begin{tabular}{lllll} 
d.f. & Cow 3 & Cow 4 & \\
\cline { 2 - 5 } & variance & $\begin{array}{l}\text { variance } \\
\text { ratio }\end{array}$ & variance & $\begin{array}{l}\text { variance } \\
\text { ratio }\end{array}$
\end{tabular}

\section{Exp. 1}

between 24-hour periods day against night periods $x$ day against night

$\begin{array}{rr}4 & 25.50 \\ 1 & 18.01 \\ 4 & 4.12\end{array}$

$\begin{array}{rrr}6.19 & 13.68 & 5.24 \\ 4.37 & 0.78 & 0.30 \\ & 2.61 & \end{array}$

Exp. 2

between 24-hour periods day against night periods $\times$ day against night

44.59
3.51
14.82

3.01

0.24

$\begin{array}{rr}33.99 & 35.99 \\ 0.42 & 0.44 \\ 0.94 & \end{array}$

Exp. 3

between 24-hour periods day against night periods $X$ day against night

$$
\begin{array}{r}
0.47 \\
25.70 \\
1.28
\end{array}
$$

$\begin{array}{rr}0.37 & 0.51 \\ 20.01 & 3.48 \\ & 0.99\end{array}$

is at least partly responsible for the relatively great variation in the mean hourly flow rate in this experiment and will have effected considerably the day-to-day variation as well as the variation in the mean hourly flow rates of the daylight and night hours (Table 2).

From Table 3 it can be seen that the variance ratio for 24-hour periods was high only in Exp. 2, cow 4. Differences between daylight and night hours were also small in all but one case. The high variance for daylight versus night hours in Exp. 3, cow 3 is not easy to explain. In general the daylight hours were more variable than the night hours. This analysis suggests that measurement of flow rate during the daytime could give a reliable estimate of the total flow. In the present experiments, the cows were fed at 12-hour intervals (Exp. 1) and at shorter intervals spread throughout the day (Exp. 2 and 3).

Fig. 2 shows the diurnal pattern of flow of duodenal digesta in the three experimental periods. The amount of digesta which flowed in every hour for each day of the 5-day collection periods are averaged and the values are shown in Fig. 2. Systematic variation
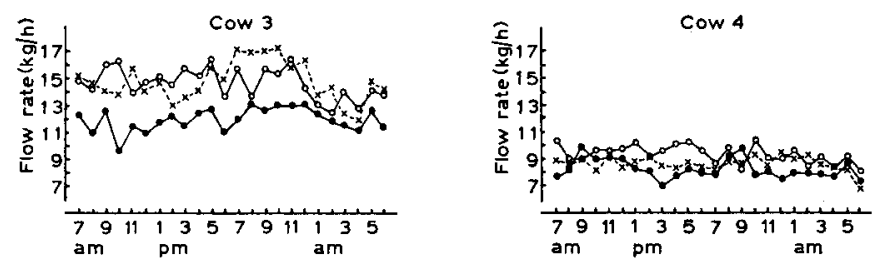

Fig. 2. The diurnal pattern of flow of duodenal digesta in cows during the three experimental periods. The quantities of duodenal contents collected every hour of each day for each of the 5 days are averaged and the mean values are given.

- Exp. 1, hay and concentrate ration;

$x$ Exp. 2, grass;

- Exp. 3, grass. 
in the flow rate was not observed, except perhaps during the late night hours in cow 3, when flow rate tended to decrease.

The flow of digesta increased shortly before feeding in both animals but this was not always reflected in an increased flow for the hour before feeding as compared with the previous hour.

\section{Variation in $\mathrm{PEG}$ and $\mathrm{Cr}_{2} \mathrm{O}_{3}$ content of digesta}

The PEG content in duodenal digesta reached a maximum at about $3-4 \mathrm{~h}$ after dosing and then decreased regularly until the next dosing time. The time interval between dosing and the start of the increase in PEG content was only about $1 \mathrm{~h}$. The content of $\mathrm{Cr}_{2} \mathrm{O}_{3}$ did not show any diurnal pattern.

The coefficients of variation of the PEG and $\mathrm{Cr}_{2} \mathrm{O}_{3}$ contents of the day samples (see above) within each 5-day period were 4.7 and $7.5 \%$ respectively.

\section{Recovery of $\mathrm{PEG}$ and $\mathrm{Cr}_{2} \mathrm{O}_{3}$ in digesta}

For the estimation of the flow of digesta by the indicator dilution method it is assumed that $100 \%$ of the dose of indicator passes the sampling point. The cumulative recovery of the indicators over the 1 st to the 5 th day of collection is shown for both cows in Fig. 3. The results for Exp. 2 are omitted from the data for the reason stated earlier. The recovery based on all hours was low over the first $24 \mathrm{~h}$ of Exp. 1, especially for $\mathrm{Cr}_{2} \mathrm{O}_{3}$, and it increased gradually with time. This pattern was much less evident in Exp. 3. The mean recovery of indicator from the duodenal digesta was $100.3 \pm 1.5 \%$ for PEG and $98.3 \pm 6.0 \%$ for $\mathrm{Cr}_{2} \mathrm{O}_{3}$ in Exp. 1 and 3. The mean recoveries based on the samples from the even hours were similar to those based on the samples from the odd hours, but recovery from the latter samples was more variable.

In Exp. 3 with cow 3, $\mathrm{Cr}_{2} \mathrm{O}_{3}$ was incompletely recovered in the duodenal contents. However, in the faeces of this cow, collected over 10 days, the $\mathrm{Cr}_{2} \mathrm{O}_{3}$ recovery was $97 \%$. During the digesta collection period, blockages in the duodenal cannula were noted on a few occasions in this cow, which might explain the irregularities in the

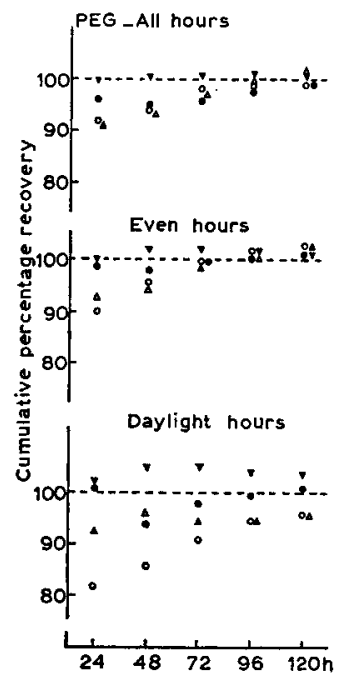

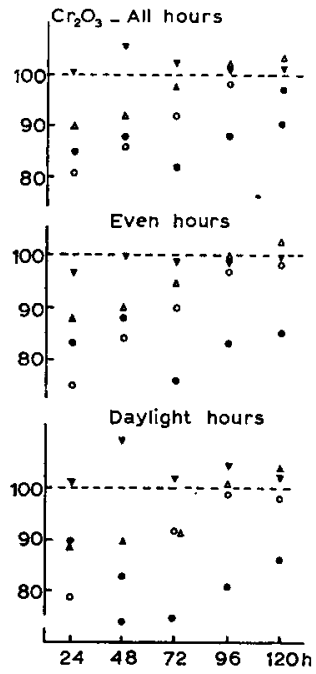

Fig. 3. Recovery (\% of dose) of poly (ethylene glycol) (PEG) and chromium sesquioxide $\left(\mathrm{Cr}_{2} \mathrm{O}_{3}\right)$ in duodenal contents of cows in relation to the length of the collection period. The cumulative recovery percentages were calculated for all hours of the day, for the even hours and for the daylight hours.

Open circles: Exp. 1, cow 3; Filled circles: Exp. 3, cow 3; Open triangles: Exp. 1, cow 4; Filled triangles: Exp. 3, cow 4. 
passage rate of $\mathrm{Cr}_{2} \mathrm{O}_{3}$. It would appear that the flow of $\mathrm{Cr}_{2} \mathrm{O}_{3}$, which was temporarily decreased during the digesta collection period, had almost fully recovered by the end of the faeces collection period.

Recovery of $P E G$ and $\mathrm{Cr}_{2} \mathrm{O}_{3}$ in faeces

The doses of PEG and $\mathrm{Cr}_{2} \mathrm{O}_{3}$ recovered in the faeces averaged $99.7 \pm 3.9 \%$ and 99.0 $\pm 5.0 \%$, respectively.

\section{Comparison of proportional and spot samples of digesta}

The contents of PEG, $\mathrm{Cr}_{2} \mathrm{O}_{3}, \mathrm{DM}, \mathrm{Ca}$ and $\mathrm{Mg}$ in the $\mathrm{P}$ and $\mathrm{NP}$ samples were compared. The results are shown in Table 4. The composition of the spot samples agreed very well with the composition of proportional samples taken during the corresponding hours. Significant differences of more than $3 \%$ were found twice in samples of cow 4 only (Exp. 2 for $\mathrm{Ca}$ and Exp. 3 for $\mathrm{Mg}$ ).

\section{Discussion}

The observations on the flow of digesta through the duodenum of re-entrant fistulated cows agreed basically with those described for sheep (Harris and Phillipson, 1962;

Table 4. Mean content of chromium sesquioxide $\left(\mathrm{Cr}_{2} \mathrm{O}_{3}\right)$, poly (ethylene glycol) (PEG), dry matter $(\mathrm{DM})$, magnesium $(\mathrm{Mg})$ and calcium (Ca) in proportional $(\mathrm{P})$ and spot (NP) samples of duodenal digesta $^{1}$ with the standard error (SE) of the difference between $P$ and NP samples.

\begin{tabular}{|c|c|c|c|c|c|c|c|}
\hline & & \multicolumn{3}{|c|}{ Cow 3} & \multicolumn{3}{|c|}{ Cow 4} \\
\hline & & \multicolumn{2}{|c|}{ Mean for } & \multirow{2}{*}{$\begin{array}{l}\text { SE of } \\
\text { difference }\end{array}$} & \multicolumn{2}{|c|}{ Mean for } & \multirow{2}{*}{$\begin{array}{l}\text { SE of } \\
\text { difference }\end{array}$} \\
\hline & & $P$ & $\mathrm{NP}$ & & $\mathbf{P}$ & NP & \\
\hline \multicolumn{8}{|l|}{ Exp. 1} \\
\hline $\mathrm{Cr}_{2} \mathrm{O}_{3}$ & $(\mathrm{mg} / \mathrm{kg})$ & 35.5 & 35.1 & 0.52 & 53.3 & 51.9 & $0.64 *$ \\
\hline PEG & $(\mathrm{g} / \mathrm{kg})$ & 0.68 & 9.69 & 0.004 & 0.98 & 0.97 & 0.007 \\
\hline DM & $(\%)$ & 3.37 & 3.35 & 0.031 & 4.18 & 4.08 & $0.039 *$ \\
\hline $\mathrm{Mg}$ & $(\mathrm{g} / \mathrm{kg} \mathrm{DM})$ & 6.02 & 6.09 & 0.077 & 3.80 & 3.82 & 0.052 \\
\hline $\mathrm{Ca}$ & (g/kg DM) & 13.31 & 13.36 & 0.171 & 14.78 & 14.97 & 0.167 \\
\hline \multicolumn{8}{|l|}{ Exp. 2} \\
\hline $\mathrm{Cr}_{2} \mathrm{O}_{3}$ & $(\mathrm{mg} / \mathrm{kg})$ & 30.7 & 30.7 & 0.57 & 45.6 & 45.5 & 0.54 \\
\hline PEG & $(\mathrm{g} / \mathrm{kg})$ & 0.58 & 0.59 & 0.005 & 0.99 & 1.01 & 0.007 \\
\hline $\mathrm{DM}$ & $(\%)$ & 2.26 & 2.27 & 0.024 & 2.55 & 2.59 & $0.021 *$ \\
\hline $\mathrm{Mg}$ & (g/kg DM) & 7.18 & 7.14 & 0.127 & 2.43 & 2.33 & 0.053 \\
\hline $\mathrm{Ca}$ & $(\mathrm{g} / \mathrm{kg} \mathrm{DM})$ & 7.87 & 7.65 & 0.112 & 7.88 & 7.61 & $0.087^{*}$ \\
\hline \multicolumn{8}{|l|}{ Exp. 3} \\
\hline $\mathrm{Cr}_{2} \mathrm{O}_{3}$ & $(\mathrm{mg} / \mathrm{kg})$ & 25.3 & 24.9 & 0.484 & 45.5 & 45.9 & 0.47 \\
\hline PEG & $(\mathrm{g} / \mathrm{kg})$ & 0.58 & 0.58 & 0.003 & 0.92 & 0.93 & $0.006^{*}$ \\
\hline DM & $(\%)$ & 2.47 & 2.47 & 0.027 & 2.89 & 2.86 & $0.019^{*}$ \\
\hline $\mathrm{Mg}$ & (g/kg DM) & 4.62 & 4.68 & 0.065 & 2.09 & 2.16 & $0.032 *$ \\
\hline $\mathrm{Ca}$ & (g/kg DM) & 11.01 & 10.92 & 0.155 & 11.33 & 11.45 & 0.107 \\
\hline
\end{tabular}

* Differences between $\mathbf{P}$ and NP samples significant at $\mathrm{P}<0.05$.

1 Each value refers to $60 \mathrm{P}$ samples and $60 \mathrm{NP}$ samples. The $\mathrm{P}$ samples were composed of $2 \%$ of the total flow for the even hours. The NP samples consisted of $200-\mathrm{ml}$ spot samples taken at $30 \mathrm{~min}$ past the even hours. 
Hogan and Phillipson, 1960; Hogan, 1964; Phillipson and Ash, 1965; Philips and Dyck, 1964; van 't Klooster et al., 1969). However, systematic diurnal variations, found in most of the sheep experiments, were either small or absent in our experiments. No relationship was noted between rate of flow of digesta and eating, ruminating or resting.

Differences in flow rate between animals and between rations were considerable and remained when flow rates were expressed as $\mathrm{kg} / \mathrm{kg} \mathrm{DM}$ intake. The highest flow rates were measured when the cows received a grass ration although the DM intake was lower in the grass rations than in the hay and concentrate ration. Similar results were reported from earlier experiments in cows (van 't Klooster and Rogers, 1969). Factors regulating the flow of digesta in the duodenum are still not well known (Hogan, 1964; Philips and Dyck, 1964; Sineshchekov, 1965; Cloethe, 1966; Bruce et al., 1966).

The daily flow rate increased from day 1 onwards in Exp. 1. Hogan and Phillipson (1960) noted an increase in flow rate through the duodenum of sheep when the digesta were not returned. However the removal of up to $5 \%$ of the duodenal digesta in experiments of Hogan (1964) did not markedly influence the flow rate. In our experiments, no more than $4 \%$ of the duodenal digesta was retained for both $P$ and NP samples. Nevertheless, the slight increase in flow rate as some experiments progressed might be regarded as a general effect of the sampling procedure.

If the indirect method of estimating the flow of digesta in the duodenum is to have acceptable accuracy, $100 \%$ of the dose of indicator(s) used should pass the duodenum. In these experiments, the mean recovery of $\mathrm{PEG}$ and $\mathrm{Cr}_{2} \mathrm{O}_{3}$ in the digesta over 5-day collection periods was very close to $100 \%$ but day-to-day variation was considerable. The recovery in the faeces over the longer balance periods was equally good. The lowest recoveries of the indicator from digesta were in the first $24 \mathrm{~h}$ in Exp. 1, when the cows were unaccustomed to the collection procedure. Cumulative recoveries improved gradually as the collection period increased to 5 days. Low recoveries of indicators from duodenal digesta have been reported frequently in collections lasting $24 \mathrm{~h}$ (Nicholson and Sutton, 1969). MacRae and Armstrong (1969) found a mean recovery of $\mathrm{Cr}_{2} \mathrm{O}_{3}$ in 17 non-consecutive 24-hour collections of $83.7 \pm 21.0 \%$ of the dose.

The procedure of total collection of digesta for short periods (12-24 h) and of adjusting the observed flow of digesta to a value equivalent to that which would give $100 \%$ recovery of the indicator(s) has been used by many workers. In our experiments, the mean flow of digesta during the first $24 \mathrm{~h}$ of each collection period was $95 \%$ of mean flow measured directly over the $120 \mathrm{~h}$ collection periods. The mean recoveries of PEG and $\mathrm{Cr}_{2} \mathrm{O}_{3}$ during the first $24 \mathrm{~h}$ were 95 and $85 \%$, respectively, of the recoveries for 120 -hour periods. These results show clearly that flow rates adjusted for $100 \%$ recovery of indicators as mentioned above, may deviate considerably from the mean flow rate, measured directly over the longer $(120 \mathrm{~h})$ period.

The motility of the reticulo-rumen is influenced by abomasal distension (Carr et al., 1970). Rumen motility influences the mixing of $\mathrm{Cr}_{2} \mathrm{O}_{3}$ and particulate matter within the rumen. Although the passage of $\mathrm{Cr}_{2} \mathrm{O}_{3}$ is not well correlated to the passage of dry matter (van 't Klooster et al., 1969; MacRae and Ulyatt, 1972) it is more likely to be associated with the particulate phase than with the fluid phase. Under certain conditions abomasal distension might reduce the number of rumen contractions and this may explain the very low recovery of $\mathrm{Cr}_{2} \mathrm{O}_{3}$ in Exp. 3, cow 3. In this instance, blockages of the duodenal cannula which were noted during the collection period may have caused abomasal distension.

The PEG content in digesta reached its maximum in 3-4 $\mathrm{h}$ after dosing and then fell regularly. Most of the variation of the mean PEG content of digesta could be attributed 
to this systematic diurnal variation. In contrast to the results of MacRae and Ulyatt (1972) in sheep, the $\mathrm{Cr}_{2} \mathrm{O}_{3}$ content of digesta did not show such a constant diurnal pattern. However, our results are similar to those found for both PEG and $\mathrm{Cr}_{2} \mathrm{O}_{3}$ content in the duodenal digesta of sheep in earlier experiments (van 't Klooster et al., 1969).

The almost complete recovery of the indicators in duodenal digesta collected over 5-day periods and the agreement in the indicator content in the proportional and spot samples of digesta show that estimates of the flow rate based on the indicator content of 60 spot samples at $2 \mathrm{~h}$ intervals can replace the direct estimates of flow digesta over 5 days with acceptable accuracy.

Using a variety of indicators, including PEG and $\mathrm{Cr}_{2} \mathrm{O}_{3}$ MacRae and Ulyatt (1972) measured the flow of digesta directly and indirectly in the duodenum of sheep. AIthough they did not compare the indirect and direct measurements simultaneously in the same animals, they also concluded that the indicator content of frequently taken spot samples gave indirect estimates of flow which were not significantly different from directly measured flow rates.

In the case of re-entrant cannulas, all the digesta must pass to the exterior. Our results showed no significant difference in the $\mathrm{DM}, \mathrm{Ca}$ and $\mathrm{Mg}$ content of the spot and proportional samples. However, in the case of simple cannulas, only a part of the digesta may pass to the exterior and it is possible that some separation of digesta might occur as a result of partial flow from the main stream out through the side arm. However, our observations on the flow of digesta from simple cannulas in cows (van 't Klooster and Rogers, 1969) and the rapid, vigorous propulsion of digesta through the duodenum and out of simple cannulas suggest that separation is unlikely to occur.

\section{Acknowledgments}

The authors thank Messrs G. A. Bangma, L. Bouknecht, O. J. Hemkes, J. A. Klein Hulze and M. J. Los for their help in managing, feeding and sampling the cows; Miss Jeanette Kolkman van Beek and Messrs J. van Dijk, A. R. Kowsolea and N. F. M. Thielen for skilled analytical assistance.

\section{References}

Bruce, J., E. O. Goodall, R. N. B. Kay, A. T. Phillipson \& L. E. Vowles, 1967. The flow of organic and inorganic materials through the alimentary tract of t'ie sheep. Proc. $R$. Soc. Lond., $B$ 166: 46.

Carr, D. H., L. M. McLeary \& D. A. Titchen, 1970. Factors affecting reflex responses of the ruminant stomach. In: A. T. Phillipson (Ed.), Physiology of digestion and metabolism in the ruminant, p. 35. Oriel Press, Newcastle upon Tyne.

Cloethe, J. G., 1966. The influence of protein intake on the digestion of dry matter in various sections of the digestive tract of the intact sheep. S. Afr. J. agric. Sci. 9: 379 .

Corbett, J. L., J. F. D. Greenhalgh, J. McDonald \& E. Florence, 1960. Excretion of chromium sesquioxide and polyethylene glycol by dairy cows. Br. J. Nutr. 14: 289.

Harris, L. E. \& A. T. Phillipson, 1962. The measurement of the flow of food to the duodenum of sheep. Anim. Prod. 4: 97.

Hogan, J. P. \& A. T. Phillipson, 1960. The rate of flow of digesta and their removal along the digestive tract of the sheep. Br. J. Nutr, 14: 147.

Hogan, J. P., 1964. The digestion of food by the grazing sheep. 1. The rate of flow of digesta. Aust. J. agric. Res. $15: 384$

Hydén, S., 1955. A turbidimetric method for the determination of higher polyethylene glycols in biological materials. Annl. K. LantbrHögsk. 22: 139. 
Kemp, A., W. B. Deijs, O. J. Hemkes \& A. J. H. van Es, 1961. Hypomagnesaemia in milking cows: intake and utilization of magnesium from herbage by lactating cows. Neth. J. agric. Sci. 9: 134.

Klooster, A. Th. van 't, P. A. M. Rogers \& H. R. Sharma, 1969. Observations on the rate of flow of digesta through the duodenum of sheep and on the recovery of polyethylene glycol and chromium sesquioxide from duodenal contents. Neth. J. agric. Sci. 17: 60.

Klooster, A. Th. van 't \& P. A. M. Rogers, 1969. Observations on the digestion and absorption of food along the gastro-intestinal tract of fistulated cows. 1. The rate of flow of digesta and the net absorption of dry matter, organic matter, ash, nitrogen and water. Meded. LandbHogesch. Wageningen 69-11: 3 .

MacRae, J. C. \& M. J. Ulyatt, 1972. Comparison of spot and continuous sampling for estimating duodenal digesta flow in sheep. N.Z. Jl agric. Res. 15: 98.

MacRae, J. C. \& D. G. Armstrong, 1969. Studies on intestinal digestion in the sheep. 1. The use of chromic oxide as an indigestible marker. Br, J. Nutr. 23: 15.

Markowitz, J., J. Archibald \& H. G. Downie, 1964. Experimental surgery, 5th ed. Williams and Wilkins, Baltimore.

Nicholson, J. W. G. \& J. D. Sutton, 1969. The effect of diet composition and level of feeding on digestion in the stomach and intestines of s'ieep. Br. J. Nutr. 23: 585 .

Philips, G. D. \& G. W. Dyck, 1964. The flow of digesta into the duodenum of sheep. Can. J. Anim. Sci. 44: 220.

Phillipson, A. T., 1952. The passage of digesta from the abomasum of sheep. J. Physiol., Lond. 166: 84.

Phillipson, A. T. \& R. W. Ash, 1965. Physiological mechanisms affecting the flow of digesta in ruminants. In: R. W. Dougherty (Ed.), Physiology of digestion in the ruminant, p. 97. Butterworths, Washington.

Rogers, P. A. M. \& A. Th. van 't Klooster, 1969. Observations on the digestion and absorption of food along the gastro-intestinal tract of fistulated cows. 3. The fate of $\mathrm{Na}, \mathrm{K}, \mathrm{Ca}, \mathrm{Mg}$ and $\mathrm{P}$ in the digesta. Meded. LandbHogesch. Wageningen 69-11: 26.

Sineshchekov, A. D., 1965. Digestion and assimilation processes in the stomach and intestines of ruminants, In: R. W. Dougherty (Ed.), Physiology of digestion in the ruminant, p. 254. Butterworths, Washington.

Topps, J. H., R. N. B. Kay \& E. D. Goodall, 1968. Digestion of concentrate and of hay diets in the stomach and intestines of ruminants. Br. J. Nutr. 22: 261. 